http://jmscr.igmpublication.org/home/

ISSN (e)-2347-176x ISSN (p) 2455-0450

crossref DOI: https://dx.doi.org/10.18535/jmscr/v9i10.03

Journal Of Medical Science And Clinical Research

\title{
Successful Retrieval of a Dismembered Peripherally inserted central catheter in the pulmonary artery: using two-step approach
}

Authors

\section{Dr Shashikant Singh, Dr Puja Singh, Dr Tutan Das}

\section{Introduction}

One of the complication of PICC is that it get dismembered $^{[1]}$. It is due to intermittent compression of PICC between $1^{\text {st }}$ rib and clavicle and between costoclavicular ligament and subclavian muscle. Fouty percent of dismembered catheter experienced embolisation ${ }^{[2]}$.

\section{Case Report}

A 65-year-old woman was a diagnosed case of post covid mucormycosis for which she was admitted in ENT department. Patient was taken for debridement for mucormycosis and was put on amphotericin B for which PICC was placed via left antecubital vein. While confirming the position of catheter it was found that distal part of catheter had embolized in pulmonary artery. Patient remain asymptomatic and was hemodynamically stable. Patient was shifted to radiology and CT pulmonary angiography was done which showed catheter in right pulmonary artery [Fig.1] and cardiology consultation was given. Patient was shifted tocath lab and percutaneous retrieval of the PICC line with use of a loop snare via the right common femoralvenous approach was planned; We initially inserted an 7Fr sheath via the right femoral vein. We then administered $5,000 \mathrm{U}$ of heparin after sheath insertion and maintained the activated clotting time between 200 and 300 s. Since distal end were within the branch of the pulmonaryarteries, it was difficult to place the loop snare at the ends of the catheter to grasp it. So Pigtail catheter was inserted and parked at main pulmonary artery [MPA]; pigtail was released at MPA and after several attempts pigtail hooked the catheter [fig 2] and it was pulled back and catheter now came into main pulmonary artery. Now pigtail catheter was taken into right ventricle and it was rotated slowly catheter got hooked [fig 3] and it was pulled back it came into inferior vena cava [IVC]. Catheter was pulled out from IVC by snare 6 French 35 $\mathrm{mm}$ [fig 4]. We were unable to place the catheter in the femoral sheath; therefore, we removed the catheter and sheath simultaneously [fig 5]. Hemostasis was easily achieved in a few minutes with manual compression, and no complications were noted.
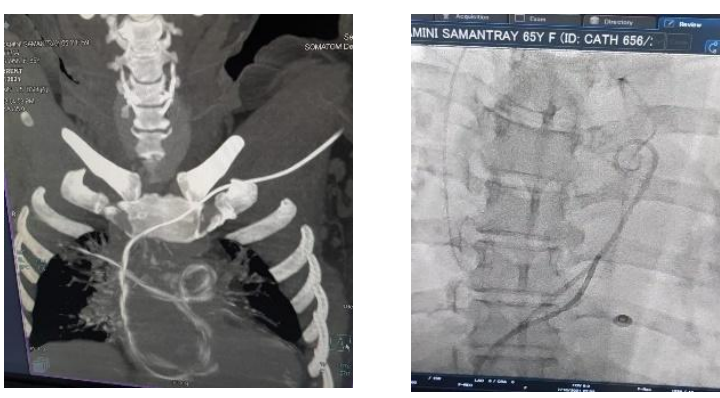


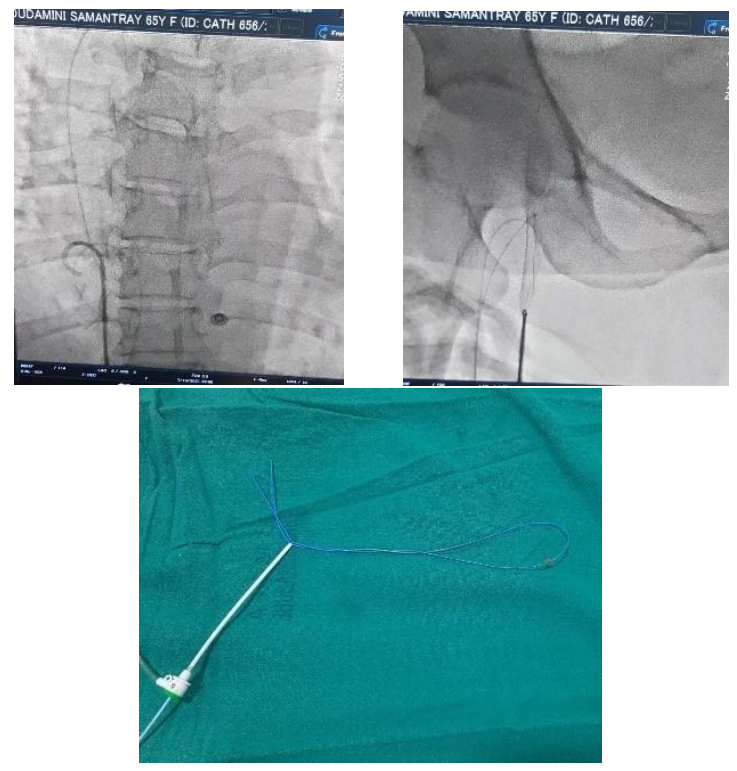

[Fig 1-5]

\section{Result}

It is difficult to retrieve dislodged catheters from the pulmonary artery, especially if the catheter is stuck to the peripheral pulmonary artery ${ }^{[3]}$. We herein describe the successful removal of a catheter stuck to the pulmonary artery using a stepwise approach. First, a pigtail catheter was used to tug the dislodged catheter in order to free the unilateral end. Then, a gooseneck snare was used to catch and pull the catheter out of the patient $^{[4]}$. The key to success is to free the end of the catheter. If we had not caught the dislodged catheter with the gooseneck snare, we would have used a homemade big-loop snare ${ }^{[5]}$.

\section{Conclusion}

Peripherally inserted central catheter fracture and migration is a rare, but serious complication, with pulmonary artery being the most frequent site of embolization. Cases unsuitable for use of loop snares, due to the ends of the catheter fragment being in inaccessible locations, can be made amenable by using a pigtail catheter to pull back the fragment to an accessible location, as described in this case.

\section{References}

1. B. Fazeny-D"orner, C. Wenzel, A. Berzlanovich et al., "Central venous catheter pinch-off and fracture: recognition,

prevention

and

Bmanagement," Bone Marrow

Transplantation, vol. 31, no. 10,pp. 927930, 2003.

2. D. H. Hinke, D. A. Zandt-Stastny, L. R. Gooodman, E. J.Quebbeman, E. A. Krzywda, and D. A. Andris, "Pinch-off syndrome: a complication of implantable subclavian venous access devices," Radiology, vol. 177, no. 2, pp. 353-356, 1990.

3. B. "Onal, B. $\mathrm{Cos}_{s}$ kun,R. Karabulut, E. T. Ilgit, Z. T"urkyilmaz, and K. S*onmez, "Interventional radiological retrieval of embolized vascular access device fragments," Diagnostic and Interventional Radiology, vol. 18, no. 1, pp. 87-91, 2012.

4. J.W. Yedlicka Jr., J. E. Carlson, D.W. Hunter, W. R. Castãneda-Z'ũniga, and K. Amplatz, "Nitinol gooseneck snare for removal of foreign bodies: experimental study and clinical evaluation,"Radiology, vol. 178, no. 3, pp. 691-693, 1991.

5. K. Yokoi, S. Sumitsuji, H. Kaneda et al., "A novel homemadesnare, safe, economical and size-adjustable," Euro Intervention, vol. 10, no. 11, pp. 13071310, 2015. 